\title{
Editorial: Knowledge management and E-learning
}

\author{
Minhong Wang and Stephen J.H. Yang \\ Editors-in-Chief
}

\begin{abstract}
Welcome to the inaugural issue of Knowledge Management \& E-Learning: An International Journal (KM\&EL).In this inaugural editorial we would like to introduce the goals of the journal and provide the basis for why this journal is needed, and outline the scope and structure of the journal.
\end{abstract}

\section{Goals of the Journal}

Fierce competition and dynamic market have forced organizations to search for new ways to improve competitive advantage. Continuous innovation becomes a goal in which knowledge is seen as the core resource and learning is viewed as the most important process. Recent research has motivated the integration of knowledge management with elearning for organizational strategic development. How knowledge management and learning apply to and affect organizations is a complicated, yet important question that requires a variety of conceptual, methodological, and technical approaches. Given an intimate connection between knowledge and learning, the high potential for synergies between them seems obvious. To facilitate the synergy, there is a need to understand and clarify the rationale of integrating knowledge management with e-learning. The goal of the journal Knowledge Management \& ELearning: An International Journal (KM\&EL) is to support and publish latest and quality research in the multidisciplinary area of knowledge management and e-learning. We hope to foster a platform for leading research in the emerging new landscape of knowledge intensive economy, which requires the integration of knowledge management and learning especially in the digital and Web-based environment.

Learning is more than consuming knowledge. The grant challenges to learning in knowledge societies are not limited to how effectively helping learners to acquire knowledge and skills, but in helping them to learn how to manage, work creatively with ideas and to contribute to the creation of new knowledge. By integrating learning with knowledge management, the understanding of education will be dramatically extended towards learning 
through practical work, lifelong learning, and self-directed learning, particularly when linked to dynamically changing circumstances.

Learning and knowledge management share a common strategy of creating a learning organization. Organizational learning implies that learning should be noted beyond individual level; an organization should be able to continuously and effectively learn and adapt to the environment. To achieve this, knowledge management is important to build an organization's intellectual assets as well as improve individual, group, and organizational performance by knowledge sharing and dissemination. Different from formal learning in educational institutions, learning in organizations serves for organizational goals and needs, and focuses on organizational systems, structures, policies, and institutional forms of knowledge to link individual and organizational learning. The challenge is to facilitate learning in such a manner that organization, technology, and pedagogy create a coherent and manageable system for working, learning and innovation.

The integration of learning and knowledge also raises the question regarding the competences of e-learning initiatives traditionally associated with the design of learning resources. Is the creation of learning resources the whole solution to e-learning, or is it more the creation of learning environment enabling learners engaged in learning and knowledge management processes for active construction and contribution of knowledge? For example, how can we facilitate the conversion between tacit and explicit knowledge, and the development and cultivation of the channels through which knowledge flows and transfers? How will future approaches to e-learning and knowledge management reflect these concerns, and how will technologies contribute? This journal aims to stimulate the investigation on the nature and future of knowledge management and e-learning.

\section{Scope and Structure of the Journal}

Research on knowledge management and e-learning covers a broad range of disciplines. The journal $K M \& E L$ provides a forum for academics and practitioners to explore research issues related to the design, implementation and deployment of knowledge management and elearning, as well as economic issues and organizational impacts. Papers 
related to all aspects of knowledge management and e-learning including theoretical and practical work offering insights into problem solving with empirical or simulation based evidence are welcome.

The journal $K M \& E L$ will publish both basic and applied research. $K M \& E L$ accepts quality research without bias to methodology. The makeup of the editorial board reflects this commitment, as we have distinguished scholars as members from a variety of disciplines and from different countries. Some of the focal points of $K M \& E L$ include but are not limited to: knowledge-based system, knowledge and information resource management, knowledge modeling and visualization, knowledge management strategies, action research for knowledge management, community of practice, organizational learning, computer supported learning, e-learning platform, e-learning in the workplace, web-based training, interactive e-learning, collaborative learning, and learning society. Furthermore, $K M \& E L$ is interested in publishing articles containing either technology development or empirical investigations addressing the value and use of knowledge management and e-learning.

Due to the diversity and the rapidly changing nature of knowledge management and e-learning, $K M \& E L$ will publish different types of articles to facilitate timely dissemination of research results and applications. $K M \& E L$ intends to publish the following types of articles:

- Research papers: These are traditional research papers describing novel research, design and implementation of knowledge management and elearning in a variety of domains, large-scale experiments, and exciting systems of relevance to the journal's academic audience as well as practitioners.

- Research notes: These are short papers that focus on state of the art thinking about a specific problem or a key innovation or new developments whose timely publication is important.

- Prototype demonstrations: These are short papers that showcase new research ideas and emerging technological solutions. These papers explain what the prototype does, why it is useful and provide a link to the working prototype so that any reader can use it either onsite or after download and local installation.

- Case studies: These studies are based on actual cases related to different issues and aspects of knowledge management and e-learning. Case studies must provide adequate information regarding the organization upon which 
the case is based, discussion of the issues involved, coverage of any experiments or trials of techniques or managerial approaches, and finally, a rich discussion of any lessons learned and or conclusions drawn from this study for research and practice.

- Book reviews: These are reviews of either textbooks or professional books relevant to knowledge management and e-learning. They provide a summary and carefully examine the strengths, and weaknesses of the book. Most importantly, reviews discuss the contribution in the context of the extant literature.

\section{Contacts}

Maggie M. Wang

Faculty of Education, Division of Information \& Technology Studies

The University of Hong Kong

Pokfulam, Hong Kong

Fax: +852-2858-5649 E-mail: magwang @ hku.hk

Website: http://web3.edu.hku.hk/magwang/

Stephen J.H. Yang

Department of Computer Science \& Information Engineering

National Central University

Taiwan

Fax: +886-3-4222681 Email: jhyang@csie.ncu.edu.tw

Website: http://jhyang.LST.ncu.edu.tw:8080/

\section{Biographical Notes}

Minhong Wang is an Assistant Professor of Information \&Technology Studies at the Faculty of Education, The University of Hong Kong. She received her $\mathrm{PhD}$ in Information Systems from City University of Hong Kong in 2005. Her current research interests include e-learning, 
knowledge management, business process management, and information systems. She has published papers in Information \& Management, Expert Systems with Applications, Knowledge-based Systems, Journal of Educational Technology and Society, and presenting papers at international conferences, including CAiSE, BPM, HICSS, AMCIS, ICEIS, PRICAI, CEC/EEE, ICELW among others. She is the Editor-inChief of Knowledge Management \& E-Learning: an International Journal $(K M \& E L)$, and serves on the Editorial Board of several journals.

Stephen J.H. Yang is a Professor of Computer Science \& Information Engineering and the Associate Dean of Academic Affairs at National Central University, Taiwan. He is the co-founders and was the CEO of T5 Corp, a company providing XML-based Web services. Dr. Yang received his $\mathrm{PhD}$ degree in Electrical Engineering \& Computer Science from the University of Illinois at Chicago in 1995. Dr. Yang has published over 160 technical papers in the areas of knowledge management, e-learning, and Internet technology. His research interests include knowledge management, mobile learning, Web 2.0, semantic Web services, social networks, context-aware and ubiquitous learning. Dr. Yang is very active in academic services. He is currently the CoEditor-in-Chief of the International Journal of Knowledge Management \& E-Learning, and the Associate Editor of the International Journal on Artificial \& Biological Intelligence Tools. In addition, Dr. Yang is on the Advisory Board of Athabasca University, School of Computing \& Information Systems, and the International Journal of Educational Technology \& Society. $\mathrm{He}$ is also on the Editorial Board of the International Journal of Web Services Research, the International Journal of Knowledge and Learning, the International Journal of Educational Technology \& Society, and the International Journal of Multimedia Data Engineering \& Management. Dr. Yang also served as the Program Co-Chair of ICCE 2008, IEEE ICALT2008, IEEE SUTC2008, IEEE ISM2008, SDPS 2008, IEEE W2ME2007, IEEE CAUL2006, and IEEE MSE2003. 